\title{
Revisiting the Barriers to and Facilitators of Research Utilization in Nursing: A Systematic Review
}

\author{
Cyruz P. Tuppal ${ }^{1}$, Paolo D. Vega ${ }^{2}$, Marina Magnolia G. Ninobla ${ }^{3}$, Mark Donald \\ Reñosa ${ }^{4}$, Abdullah Al-Battashi ${ }^{5}$, Glenda Arquiza ${ }^{6}$, Elizabeth P. Baua ${ }^{1}$ \\ ${ }^{\text {I} S t . ~ P a u l ~ U n i v e r s i t y ~ P h i l i p p i n e s ~ S y s t e m, ~ T u g u e g a r a o ~ C i t y, ~ C a g a y a n ~ V a l l e y ~}$ \\ ${ }^{2}$ Mount Sinai St. Luke's Hospital, New York, United States of America \\ ${ }^{3}$ College of Nursing, Muscat Branch, Sultanate of Oman \\ ${ }^{4}$ Research Institute for Tropical Medicine - Department of Health, Philippines \\ ${ }^{5}$ Oman Specialty Medical Board, Muscat, Sultanate of Oman \\ ${ }^{6}$ Philippine Regulation Commission, Manila, Philippines \\ Corresponding Author: Cyruz P. Tuppal (drcyruztuppal@gmail.com)
}

\begin{abstract}
Background: Nursing profession continues to evolve, expand, and link its practice that requires evidence to strengthen its body of knowledge, and research utilization (RU) is pivotal towards this realization.

Purpose: This systematic review aimed to critically identify, select, appraise, and synthesize research evidence about the barriers to and facilitators of research utilization. Methods: There were 17,961 papers during the initial database search and 85 papers from other sources from the electronic databases including Web of Science, CINAHL, Complete, Scopus, OVID, Medline, PsychInfo, SocIndex, Internurse, British Nursing Index, ERIC, and PubMed. After further analysis, thirty-six articles were included in the analysis that explicitly identified and described the barriers to and facilitators of research utilization in nursing.

Results: Based on the findings, the lack of awareness about research, lack of authority to change their practice, overwhelming publications, and lack of compiled literature were the topmost identified barriers to research utilization. On the other hand, organizational and colleague support, and continuing education as both personal and professional commitment can further facilitate research utilization.

Conclusion: Despite extensive studies conducted addressing the barriers to research utilization, the findings suggest a consistent reproach on the capability of nurses to maximize and utilize research. The same elements that may serve as barriers can likewise become the impetus in gaining sufficient research utilization among nurses.
\end{abstract}

Keywords: Barriers; facilitators; nursing; research utilization; systematic review

\section{BACKGROUND}

The nursing profession continues to evolve, expand, and link its practice on the evidence as the groundwork to strengthen its body of knowledge through research. From the time the National Center for Nursing Research (NCNR) was created, research has become "a sign of the profession's status, power, and acknowledged the contribution to the health of the American public" (D'Antonio, 1997, p. 105). "The NCNR is a 
turning point in the history of nursing research that further broadens the opportunities of various scientific investigations. During the infancy stage of nursing research, the focus was nursing concepts, roles, and professional programs" (p. 204). The graduate programs focused on nursing procedures, war-related and military services, workforce distribution, costs of services, and nursing education. There was also an apparent demand during the post-World War II for the standardization of practice, qualification of nurses, inclusion of mental health services, student, and professional attributes along with the process of socialization grounded in social sciences.

Gortner (1980) also emphasized the emerging focus on career mobility to advance practice, opportunities for education, and training for the nurse scientists. Added to this landmark was the growth of practice-related research during the 1970s, including disease-specific therapeutic modalities, either actual or potential health needs of the diverse patient population and nurse-patient relationships. Throughout the 1980s, theory development was highlighted for nurse scientists "to think, to examine, to analyze, and to synthesize" elements for the advancement of nursing as a discipline interwoven in education, research and practice (Harriet, 1980). From then and way forward, the focus of nursing research becomes multifaceted to address the patient demands, the everchanging status of healthcare, demographic shift, radical reforms, and globalization. Gortner (1980) from his seminal work, noted that nursing would continue to search for knowledge on health promotion, illness prevention, curative, rehabilitation, and restoration. The union of nursing and technology serves as an impetus addressing the biomedical, behavioral, and clinical sciences to advance practice along with the research utilization (Bostrom \& Suter, 1993; Estabrooks, Winther, \& Derksen, 2004).

In the recent development, the practice of nursing has presented scientific and authoritative credence as a discipline. However, as the new millennium unfolds, it also poses immeasurable threats and research has been considered to be a pivotal instrument to strengthen the profession's resilience and adaptability. Nurses need to use research findings, and through research utilization, the best practices and substantial evidence will lead to better practice, improve patient outcomes, and inform policymaking bodies. Moving to a more important realization, nurses should better start addressing those barriers to and facilitators of research utilization.

\section{PURPOSE}

This study employed a systematic review of the literature to identify, select, appraise, and synthesize research evidence on barriers to and facilitators of research utilization in nursing.

\section{METHODS}

A systematic review was used in this study. Both quantitative and qualitative studies were aggregated to develop a deeper understanding of barriers to and facilitators of RU. The authors performed computerized searches from the Web of Science, CINAHL Complete, Scopus, ERIC, OVID, Medline, PsychInfo, SocIndex, Internurse, British Nursing Index, and PubMed using the keywords 'barriers,' 'facilitators,' 'research utilization,' or 'research utilisation,' 'nurse,' and 'nursing.' A supplemental hand searching that involved a manual page-by-page examination of the entire content of a 
journal issue to avoid bias in a keyword search was also conducted. The retrieved articles were imported by using a reference manager and were screened based on the prespecified selection criteria.

Final criteria for single publication were studies with an explicit focus on barriers to and facilitators of research utilization, reports of empirical data (qualitative and quantitative); and articles in English published in January 2007 through October 2017. Newspapers, magazines, images, conference summaries, dissertation, and poetry were excluded. There were 17,961 papers during the initial database search and 85 papers from other sources. When limits were applied, there were 3,369 articles, of which 14,182 were removed as duplicates. Three hundred fifty-five (355) were included for full-text review, 36 articles for final screening, and 36 for final inclusion. Figure 1 shows the PRISMA Flow Chart detailing the results of the search summary.

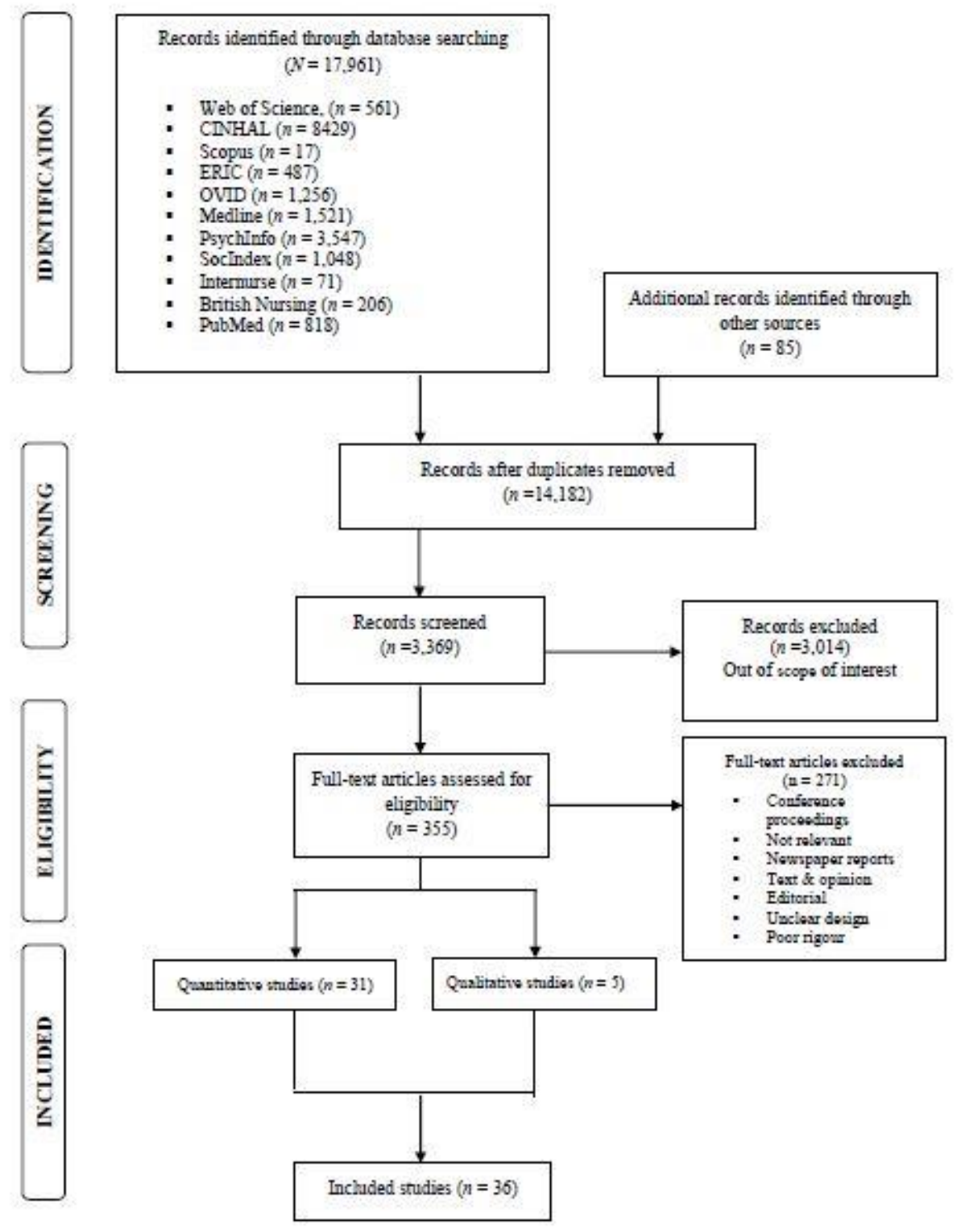

Figure 1. PRISMA Flow chart detailing of studies through the review 
The authors reviewed the articles in three phases. In Phase 1, all included articles underwent a double-blind review of whether to reject or accept the articles (CT/PV/MDR). In Phase 2, all records were reviewed for the full details (CT/PV/MN/MDR/AA). Many articles contained incomplete information, including the abstract and title, introduction and aims, data analysis, ethics and bias, findings or results, transferability/generalizability, and implications and usefulness. In Phase 3, the scoring for methodological rigor involved the assessment of the articles based on abstract \& title, introduction, and aims, method and data, sampling, data analysis, ethics and bias, findings/results, transferability/generalizability, implications and usefulness using a four-point Likert scale (4=good, 3=fair, 2=poor, and $1=$ very poor) by five authors independently. Reviewers reached consensus during a disagreement about the retrieved articles (CT/PV/MN/MDR/AA). The country of origin, study design, sample, setting, barriers, and facilitators were systematically coded.

\section{RESULTS}

\section{Characteristics of studies}

Thirty-six studies in this review include seven (7) from the United States of America, five (5) from Turkey, three (3) from China, two each (2) from the Kingdom of Saudi Arabia, South Korea, and Iran. Other articles were from Sweden, Hongkong Taiwan, Bahrain, Austria, Spain, Greece, Jordan, Nepal, Norway, Australia, and Kenya. Thirty (30) quantitative studies were identified using descriptive, cross-sectional, and correlational or a combined approach. One (1) quasi-experimental pre-posttest design was noted. Five (5) qualitative studies, among them three (3) literature reviews, one (1) systematic review, and one (1) grounded theory approach.

Funk, Champagne, Wiese, and Tornquist (1991) initially developed the 28-item Barriers to Research Utilization Scale (BRUS), the Conduct and Utilization of Research in Nursing (CURN) Project Research Utilization Questionnaire. Two studies used this original version, and others had the modified 29-item with four factors (adopter/nurse, organization/setting, innovation/research, and communication/presentation). Overall, BRUS had high reliability, and content validity from various studies across countries and population from the 1990s to 2000s translated to different languages like Spanish, Chinese, Korean, Persian, and Turkish.

The sample nurses surveyed from different settings were from tertiary public hospitals, gerontological nursing homes, university teaching hospital, specialty pediatric hospital, primary care centers, and traditional Chinese medicine tertiary-level hospital. The sample size among nurses ranged from 63 to 1,487 while focus group among public health nurses had sixteen.

\section{Quality scores of articles included}

Table 1 shows the results of quality appraisal scores. The included studies were reviewed and graded based on the abstract \& title, introduction and aims, method and data, sampling, data analysis, ethics and bias, findings/results, transferability/ generalizability, implications, and usefulness. The independent review and appraisal scores ranged from 92\% - 97\% (Hawker, Payne, Kerr, Hardey, \& Powell, 2002). A 
meta-analysis was not appropriate due to the variation of the type of outcome measures. Hence, content analysis was undertaken.

\section{Barriers to facilitators of research utilization}

Table 2 shows the topmost barriers to RU based on the following domains: adopter/ nurse, organization/setting, innovation/research, and presentation communication. Seven articles found nurses to have a lack of awareness about research (adopter/nurse). Twenty-one (21) articles indicate a lack of authority to change practice (organization/ setting). Three (3) articles reported overwhelming publications (innovation/research) and four (4) articles indicated a lack of available relevant literature compilation (communication/presentation). The topmost facilitators of research utilization highlighted in this review: organizational support; colleague support and continuing education as personal and professional commitment.

\section{DISCUSSION}

RU has gained much recognition in the past recent years and continued to attract attention (Estabrooks et al., 2004). From an early commentary, Gift (1994) mentioned that RU is "the use of research findings as a basis for practice" (p. 306). Estabrooks et al. (2004) mentioned that as early as the 1970s, research-based projects proliferated due to the demands of the advancements in nursing practice in the United States, Canada, and the United Kingdom. Using a bibliometric analysis, Estabrooks et al. (2004) found RU as a topic existed in 630 articles between 1981 to 2001 in 194 journals. Among them, there were 350 opinion articles, 65 conceptual articles, 112 clinical research utilization studies, and 103 research articles. Estabrooks et al. (2004) highlighted three significant reasons why RU has not been fully implemented including interdisciplinary collaboration has not yet occurred, less evidence of active programmatic research and research utilization as a scholarship is more renounced among the developed countries.

The findings in this review revealed that despite the knowledge diffusion and advancement in technology, and advocacy on research capacity-building in many organizations, nurses are still caught unaware of the research. Nurses had low direct participation and involvement in research and did not attend any postgraduate courses that could reduce barriers. The lack of awareness about research could also be related to the nurses' daily work that demands much of their time, and nurses' attributes for being task-oriented and role-focused in direct patient care. Moreover, nurses tend to focus on the role at hand and engage heavily in regular unit roles and responsibilities. In addition to this focus, specialized nurses are heavily engaging themselves in the technical and advanced skills performed in specialized units. Other reason could be the nurses' feeling of isolation from knowledgeable colleagues (Kocaman et al., 2010). Nurses who feel that they have been away from studying for a more extended period and are discouraged perceive that they do not have any research involvement. The so-called theory-practice gap may have also contributed to the feeling of isolation.

It should be noted that lack of facilities highlighted in some other studies also yields a lack of awareness among nurses including adequate resources, education and training, and policies where support from the organization should be prioritized. The lack of authority to change practice is reported in many studies. This finding echoed the studies 
from Saudi and Bahrain where Omer (2012) surmised, "Saudi hospitals are administered either under the medical or operational department, a status that reduces nursing department autonomy" (p. 71). Buhaid, Lau, and O'Connor (2014) mentioned that empowerment is imperative for nurses despite bureaucratic demands of a hierarchical organization exist. According to Kang (2015), the conditions of work empowerment are significant predictors of the three barriers: adopter (nurse), organization (setting), and communication (research). Nurses feel that they lack authority to change a practice that is related to factors such as resistance to change, complacency in the existing routine practices, lack of managerial support, as well as lack of policies and regulations to support some of these changes. For example, students are taught in their diploma, bachelors, or post-graduate studies to practice in a specific manner as per the international standards. However, when these students or graduates go to clinical settings, they see different practices leading to a theory-practice gap. When such students or graduates attempt to create changes through RU, there is limited support in the system that allows them to make the desired changes.

Nurses also reported an overwhelming publication requirement, and institutional approval is not made readily available. This finding suggests that nurses who would wish to publish their articles take some time for the review process and publication. This is particularly evident in bureaucratic organizations where there are rules and regulations and multiple levels of approvals for moving research work forward. Highranking peer-refereed journals have their window review period to ensure conformity to their guidelines. Nurses should understand the rigorous process of review but should not be discouraged. Nurses should always have the intrinsic motivation for research activities and move forward with RU as an integral part of improving their practice and providing high-quality care for their patients and their communities.

The lack of relevant literature compilation is another barrier. Nurses would appreciate if there were available and more accessible resources that they could use whenever they need even for reading or actual research conduct. For instance, the library journal subscriptions that should be in place and the availability of such resources would encourage nurses and be an excellent motivator for them in initiating and moving their research work forward. Schoonover (2009) contends that this barrier is perhaps due to a lack of knowledge and skills to access and search electronic databases.

Also, the results indicate that organizational support is an essential driver of RU and consistently mentioned in international literature. Organizational support is critical in RU, specifically in bureaucratic organizations where approvals and funding are a lengthy process. The organization can provide funding, infrastructures, and facilities for research. However, developing countries need to strive in building hybrid facilities for research. The government-owned universities and healthcare organizations have a limited budget to make RU as feasible and implementable as possible.

Colleague support is also another driver of RU. Those who have experience can assist nurses in developing their research skills in various phases (e.g., conceptualization, empirical, analytical, dissemination, and utilization). Colleague support is an asset to organizations and an essential method for nurses to commence and initiate the process 
of research. On the one hand, the multidisciplinary collaboration between academic and service partnerships are in existence to date. The collegial partnerships would yield mentored participation to motivate nurses, enhance their involvement, and heighten their commitment.

Moreover, nurses would have inner motivation to conduct research, pursue postgraduate courses, and eventually utilize their findings to inform practice, and build authority. It is worth noting that the so-called 'theory-practice' is an essential challenge to the initiation of research and RU. The concept of research is made complicated and confusing by academics and educators, while educators and academics do not understand the practice setting. Clinicians perhaps do not understand all aspects of research. Hence, the gap becomes more prominent.

Another aspect that is important in this context is that research is the least emphasized aspect of educational preparation due to curriculum constraints, as well as the focus of the curriculum, is more on the acquisition of knowledge and skills aspects such as critical thinking, patient history and assessment, and on other management patient aspects, but not on research. One crucial issue that should be considered within the area of RU is the role of the nurse that poses a challenge, particularly the specialized nurse or midwife. The role of the specialized nurse and midwife poses a constraint to their desire and ability to participate in research activities because of the increased workloads, time constraints, as well as staff shortages.

Results indicate that there need to be concerted efforts for healthcare professionals, specifically nurses, to enhance RU in all aspects of their practice and professional careers. Efforts should be geared for nurses to promote research-based activities. These include but not limited to critical decision making "clinical challenging," critiquing and appraising of the available evidence, capitalizing on available resources, partnerships between academics and clinicians, collaboration with administrators, and designing clinical studies. The results of the study deploy a possible avenue to help improve the present and future patient outcomes. Nurse educators and clinical nurse educators must fulfill the call to serve as role models and facilitators of evidence-based nursing through learning activities. Likewise, as nurses are expected to be the primary caregivers be it inside or outside the confines of the hospital, the identification of favorable and adverse research utilization imposes a very significant impact for evidence-based nursing care. It is seemingly apparent that there exists a gap to support the goals for a more scientific approach to nursing practice when the barriers to research utilization are present within clinical practice settings. These have made it difficult for nurses to fully absorb the possible benefits of RU and incorporate these to help advance evidence-based nursing practice.

\section{CONCLUSION}

This review showed that the lack of awareness about research, lack of authority to change their practice, overwhelming publications, and lack of compiled literature are the topmost identified barriers to RU. Meanwhile, organizational and colleague support and continuing education as both personal and professional commitment are found to facilitate research utilization further. Despite extensive studies conducted addressing the 
barriers to RU, the findings suggest a consistent reproach on the capability of nurses to maximize and utilize research. With the same elements that may serve as barriers to, can likewise become the impetus in gaining sufficient RU among nurses. The prime movers identified to encourage RU among nurses can be deduced in the provision of adequate support, extending from the organizational to collegial and to personal self-motivation pursuit to excellence, the nursing profession endures to evolve. To fully realize the implementation of RU in nursing, the barriers, as mentioned in this review, should be addressed primarily those that limit nurses' scope of practice.

\section{CONFLICT OF INTEREST}

The authors declare no conflict of interest.

\section{REFERENCES}

Aboshaiqah, A. E., Qasim, A., Al Bashaireh, A., \& Patalagsa, J. G. (2014). Nurses' perception of barriers to research utilization in a public hospital in Saudi Arabia. Saudi Medical Journal, 35(9), 1136-1139.

Al Khalaileh, M., Al Qadire, M., Musa, A., Al-Khawaldeh, O., Al Qudah, H., \& Alhabahbeh, A. (2016). Closing the gap between research evidence and clinical practice: Jordanian nurses' perceived barriers to research utilization. Journal of Education and Practice, 7(8), 52-57.

Athanasakis, E. (2013). Nurses' research behavior and barriers to research utilization into clinical nursing practice: A closer look. International Journal of Caring Sciences, 6(1), 16-28.

Atkinson, M., Turkel, M., \& Cashy, J. (2008). Overcoming barriers to research in a magnet community hospital. Journal of Nursing Care Quality, 23(4), 362-368.

Austvoll-Dahlgren, A., \& Helseth, S. (2012). Public health nurses' barriers and facilitators to the use of research in consultations about childhood vaccinations. Scandinavian Journal of Caring Sciences, 26(2), 271-278. doi:10.1111/j.14716712.2011.00928.x

Boström, A.-M., Kajermo, K. N., Nordström, G., \& Wallin, L. (2008). Barriers to research utilization and research use among registered nurses working in the care of older people: Does the barriers scale discriminate between research users and non-research users on perceptions of barriers? Implementation Science, 3, 24-24. doi:10.1186/1748-5908-3-24

Bostrom, J., \& Suter, N. W. (1993). Research utilization: Making the link to practice. Journal of Nursing Staff Development, 9(1), 28-34.

Breimaier, H. E., Halfens, R. J. G., \& Lohrmann, C. (2011). Nurses' wishes, knowledge, attitudes, and perceived barriers on implementing research findings into practice among graduate nurses in Austria. Journal of Clinical Nursing, 20(11-12), 1744-1756. doi:10.1111/j.1365-2702.2010.03491.x

Brown, C. E., Ecoff, L., Kim, S. C., Wickline, M. A., Rose, B., Klimpel, K., \& Glaser, D. (2010). Multi-institutional study of barriers to research utilization and evidence-based practice among hospital nurses. Journal of Clinical Nursing, 19(13-14), 1944-1951. doi:10.1111/j.1365-2702.2009.03184.x

Buhaid, N., Lau, R., \& O'Connor, M. (2014). A survey of nurses' perceived barriers to research utilization in Bahrain in comparison to other countries. Middle East Journal of Nursing, 8(2), 3-9. 
Chang, H. C., Russell, C., \& Jones, M. K. (2010). Implementing evidence-based practice in Taiwanese nursing homes: Attitudes and perceived barriers and facilitators. Journal of Gerontological Nursing, 36(1), 41-48. doi:10.3928/00989134-20091204-04

Chau, J. P. C., Lopez, V., \& Thompson, D. R. (2008). A survey of Hongkong nurses' perceptions of barriers to and facilitators of research utilization. Research in Nursing and Health, 31(6), 640-649. doi:10.1002/nur.20289

Chen, S. H., Shao, J. H., Hsiao, Y. C., \& Lee, H. C. (2013). Barriers to research utilization by registered nurses in Taiwan. Research in Nursing and Health, 36(2), 191-202. doi:10.1002/nur.21521

Chien, W. T., Bai, Q., Wong, W. K., Wang, H., \& Lu, X. (2013). Nurses' perceived barriers to and facilitators of research utilization in mainland China: A crosssectional survey. Open Nursing Journal, 7(1), 96-106.

Cline, G. J., Burger, K. J., Amankwah, E. K., Goldenberg, N. A., \& Ghazarian, S. R. (2017). Promoting the utilization of science in healthcare (push) project: A description of the perceived barriers and facilitators to research utilization among pediatric nurses. Journal for Nurses in Professional Development, 33(3), 113-119. doi:10.1097/nnd.0000000000000345

D'Antonio, P. (1997). Toward a history of research in nursing. Nursing Research, 46(2), 105-110. doi:10.1097/00006199-199703000-00008

Estabrooks, C. A., Winther, C., \& Derksen, L. (2004). Mapping the field: A bibliometric analysis of the research utilization literature in nursing. Nurs Res, 53(5), 293-303.

Funk, S. G., Champagne, M. T., Wiese, R. A., \& Tornquist, E. M. (1991). Barriers: The barriers to research utilization scale. Applied Nursing Research, 4(1), 39-45. doi:10.1016/S0897-1897(05)80052-7

Gift, G. A. (1994). Nursing research utilization. Clinical Nurse Specialist, 8(6), 306306. doi:10.1097/00002800-199411000-00005

Gortner, S. R. (1980). Nursing research: Out of the past and into the future. Nursing Research, 29(4), 204-206.

Harriet, F. R. (1980). Nursing research in the 1980s: Issues and implications. Advances in Nursing Science, 3(1), 85-92. doi:10.1097/00012272-198010000-00009

Hawker, S., Payne, S., Kerr, C., Hardey, M., \& Powell, J. (2002). Appraising the evidence: Reviewing disparate data systematically. Qualitative Health Research, 12(9), 1284-1299. doi:10.1177/1049732302238251

Hendricks, J., \& Cope, V. (2017). Research is not a 'scary' word: Registered nurses and the barriers to research utilization. Nordic Journal of Nursing Research, 37(1), 44-50.

Heydari, A., \& Emami Zeydi, A. (2014). Barriers to and facilitators of research utilization among Iranian nurses: A literature review. Journal of Caring Sciences, 3(4), 265-275. doi:10.5681/jcs.2014.029

Kang, H. (2015). Geriatric hospital nurses' perceived barriers to research utilization and empowerment. Asian Nursing Research, 9(1), 65-72. doi:10.1016/j.anr.2014.11.005

Kocaman, G., Seren, S., Lash, A. A., Kurt, S., Bengu, N., \& Yurumezoglu, H. A. (2010). Barriers to research utilization by staff nurses in a university hospital. Journal of Clinical Nursing, 19(13-14), 1908-1918. doi:10.1111/j.13652702.2009.03032.x 
Mehrdad, N., Salsali, M., \& Kazemnejad, A. (2008). The spectrum of barriers to and facilitators of research utilization in Iranian nursing. Journal of Clinical Nursing, 17(16), 2194-2202. doi:10.1111/j.1365-2702.2007.02040.x

Morenso-Casbas, T., Fuentelsaz-Gallego, C., de Miguel, A. G., Gonzalez-Maria, E., \& Clarke, S. P. (2011). Spanish nurses' attitudes towards research and perceived barriers and facilitators of research utilization: A comparative survey of nurses with and without experience as principal investigators. Journal of Clinical Nursing, 20(13-14), 1936-1947. doi:10.1111/j.1365-2702.2010.03656.x

Mutisya, A., Karani, A., \& Kigondu, C. (2015). Research utilization among nurses at a teaching hospital in Kenya. Journal of Caring Sciences, 4(2), 95-104. doi: $10.15171 /$ jcs. 2015.010

O'Nan, C. L. (2011). The effect of a journal club on perceived barriers to the utilization of nursing research in a practice setting. Journal for Nurses in Staff Development, 27(4), 160-164. doi:10.1097/NND.0b013e31822365f6

Oh, E. G. (2008). Research activities and perceptions of barriers to research utilization among critical care nurses in Korea. Intensive and Critical Care Nursing, 24(5), 314-322. doi:10.1016/j.iccn.2007.12.001

Omer, T. (2012). Research utilization in a multicultural nursing setting in Saudi Arabia: Barriers and facilitators. Journal of Nursing Research, 20(1), 66-73. doi:10.1097/JNR.0b013e31824777d8

Sanjari, M., Baradaran, H. R., Aalaa, M., \& Mehrdad, N. (2015). Barriers and facilitators of nursing research utilization in Iran: A systematic review. Iranian Journal of Nursing and Midwifery Research, 20(5), 529-539. doi:10.4103/17359066.164501

Sari, D., Turgay, A. S., Genc, R. E., \& Bozkurt, O. D. (2012). Research activities and perceptions of barriers to research utilization among Turkish nurses. Journal of Continuing Education in Nursing, 43(6), 251-258. doi:10.3928/0022012420111115-05

Schoonover, H. (2009). Barriers to research utilization among registered nurses practicing in a community hospital. Journal for Nurses in Staff Development, 25(4), 199-212. doi:10.1097/NND.0b013e3181ae145f

Solomons, N. M., \& Spross, J. A. (2011). Evidence-based practice barriers and facilitators from a continuous quality improvement perspective: An integrative review. Journal of Nursing Management, 19(1), 109-120. doi:10.1111/j.13652834.2010.01144.x

Srijana, K. C., Raj Subramaniam, P., \& Paudel, S. (2016). Barriers and facilitators of utilizing research among nurses in Nepal. Journal of Continuing Education in Nursing, 47(4), 171-179. doi:10.3928/00220124-20160322-07

Strickland, R. J., \& O'Leary-Kelley, C. (2009). Clinical nurse educators' perceptions of research utilization: Barriers and facilitators to change. Journal for Nurses in Staff Development, 25(4), 164-171. doi:10.1097/NND.0b013e3181ae142b

Tan, M., Sahin, Z. A., \& Ozdemir, F. K. (2012). Barriers of research utilization from the perspective of nurses in eastern Turkey. Nursing Outlook, 60(1), 44-50. doi:10.1016/j.outlook.2011.07.002

Uysal, A., Temel, A. B., Ardahan, M., \& Ozkahraman, S. (2010). Barriers to research utilisation among nurses in Turkey. Journal of Clinical Nursing, 19(23-24), 34433452. doi:10.1111/j.1365-2702.2010.03318.x 
Wang, L.-P., Jiang, X.-L., Wang, L., Wang, G.-R., \& Bai, Y.-J. (2013). Barriers to and facilitators of research utilization: A survey of registered nurses in China. PloS One, 8(11), e81908-e81908. doi:10.1371/journal.pone.0081908

Yadav, B. L., \& Fealy, G. M. (2012). Irish psychiatric nurses' self-reported barriers, facilitators and skills for developing evidence-based practice. Journal of Psychiatric and Mental Health Nursing, 19(2), 116-122. doi:10.1111/j.13652850.2011.01763.x

Yava, A., Tosun, N., Cicek, H., Yavan, T., Terakye, G., \& Hatipoglu, S. (2009). Nurses' perceptions of the barriers to and the facilitators of research utilization in Turkey. Applied Nursing Research, 22(3), 166-175. doi:10.1016/j.apnr.2007.11.003

Zhou, F., Maier, M., Hao, Y., Tang, L., Guo, H., Liu, H., \& Liu, Y. (2015). Barriers to research utilization among registered nurses in traditional Chinese medicine hospitals: A cross-sectional survey in China. Evidence-Based Complementary And Alternative Medicine: Ecam, 2015, 475340-475340. doi:10.1155/2015/475340 


\section{Appendixes}

Table 1. Quality appraisal scores

\begin{tabular}{|c|c|c|c|c|c|c|c|c|c|c|c|}
\hline Authors & Country & 1 & 2 & 3 & 4 & 5 & 6 & 7 & 8 & 9 & $\begin{array}{c}\text { Appraised } \\
\text { Studies }\end{array}$ \\
\hline Aboshaiqah, Qasim, Al Bashaireh, and Patalagsa (2014) & Kingdom of Saudi Arabia & 4 & 4 & 4 & 4 & 4 & 3 & 3 & 4 & 4 & $94 \%$ \\
\hline $\mathrm{Al}$ Khalaileh et al. (2016) & Jordan & 4 & 4 & 3 & 3 & 4 & 4 & 4 & 4 & 4 & $94 \%$ \\
\hline Athanasakis (2013) & Greece & 4 & 4 & 4 & 4 & 4 & 3 & 4 & 4 & 3 & $94 \%$ \\
\hline Atkinson, Turkel, and Cashy (2008) & USA & 4 & 4 & 4 & 4 & 4 & 4 & 4 & 4 & 3 & $97 \%$ \\
\hline Austvoll-Dahlgren and Helseth (2012) & Norway & 4 & 4 & 4 & 4 & 4 & 4 & 4 & 3 & 3 & $94 \%$ \\
\hline Boström, Kajermo, Nordström, and Wallin (2008) & Sweden & 4 & 4 & 4 & 4 & 4 & 4 & 4 & 3 & 4 & $97 \%$ \\
\hline Breimaier, Halfens, and Lohrmann (2011) & Austria & 4 & 4 & 4 & 4 & 4 & 4 & 3 & 4 & 4 & $97 \%$ \\
\hline Brown et al. (2010) & USA & 4 & 4 & 4 & 3 & 4 & 4 & 3 & 4 & 4 & $94 \%$ \\
\hline Buhaid et al. (2014) & Bahrain & 4 & 4 & 4 & 4 & 4 & 3 & 4 & 4 & 4 & $97 \%$ \\
\hline Chang, Russell, and Jones (2010) & Taiwan & 4 & 4 & 4 & 4 & 4 & 4 & 4 & 3 & 4 & $97 \%$ \\
\hline Chau, Lopez, and Thompson (2008) & Hongkong & 4 & 4 & 4 & 4 & 4 & 3 & 4 & 4 & 4 & $97 \%$ \\
\hline Chen, Shao, Hsiao, and Lee (2013) & Taiwan & 4 & 4 & 4 & 4 & 4 & 3 & 4 & 4 & 4 & $97 \%$ \\
\hline Chien, Bai, Wong, Wang, and Lu (2013) & China & 4 & 4 & 4 & 4 & 4 & 3 & 4 & 4 & 4 & $97 \%$ \\
\hline $\begin{array}{l}\text { Cline, Burger, Amankwah, Goldenberg, and Ghazarian } \\
\text { (2017) }\end{array}$ & USA & 4 & 4 & 4 & 4 & 4 & 4 & 4 & 3 & 4 & $97 \%$ \\
\hline Hendricks and Cope (2017) & Australia & 4 & 4 & 4 & 3 & 4 & 4 & 4 & 4 & 4 & $97 \%$ \\
\hline Heydari and Emami Zeydi (2014) & Iran & 4 & 3 & 4 & 4 & 4 & 4 & 4 & 3 & 4 & $94 \%$ \\
\hline Kang (2015) & South Korea & 4 & 4 & 4 & 4 & 4 & 4 & 3 & 3 & 4 & $94 \%$ \\
\hline Kocaman et al. (2010) & Turkey & 4 & 4 & 4 & 4 & 4 & 4 & 3 & 4 & 4 & $97 \%$ \\
\hline Mehrdad, Salsali, and Kazemnejad (2008) & Iran & 4 & 4 & 4 & 4 & 4 & 3 & 3 & 4 & 4 & $94 \%$ \\
\hline $\begin{array}{l}\text { Morenso-Casbas, Fuentelsaz-Gallego, de Miguel, } \\
\text { Gonzalez-Maria, and Clarke (2011) }\end{array}$ & Spain & 4 & 3 & 4 & 4 & 4 & 4 & 4 & 4 & 3 & $94 \%$ \\
\hline Mutisya, Karani, and Kigondu (2015) & Kenya & 4 & 4 & 4 & 4 & 4 & 4 & 4 & 4 & 3 & $97 \%$ \\
\hline O'Nan (2011) & USA & 4 & 4 & 4 & 4 & 4 & 4 & 4 & 3 & 4 & $97 \%$ \\
\hline Oh (2008) & Korea & 4 & 4 & 4 & 4 & 4 & 4 & 3 & 4 & 4 & $97 \%$ \\
\hline Omer (2012) & KSA & 4 & 3 & 4 & 4 & 3 & 3 & 4 & 4 & 4 & $92 \%$ \\
\hline Sanjari, Baradaran, Aalaa, and Mehrdad (2015) & Iran & 4 & 4 & 4 & 4 & 4 & 3 & 4 & 4 & 4 & $97 \%$ \\
\hline Sari, Turgay, Genc, and Bozkurt (2012) & Turkey & 4 & 4 & 4 & 4 & 4 & 4 & 3 & 4 & 4 & $97 \%$ \\
\hline Schoonover (2009) & USA & 4 & 4 & 4 & 4 & 4 & 4 & 3 & 4 & 3 & $94 \%$ \\
\hline Solomons and Spross (2011) & USA & 4 & 4 & 4 & 3 & 4 & 4 & 4 & 4 & 4 & $97 \%$ \\
\hline Srijana, Raj Subramaniam, and Paudel (2016) & Nepal & 4 & 4 & 4 & 4 & 4 & 4 & 3 & 4 & 4 & $97 \%$ \\
\hline Strickland and O'Leary-Kelley (2009) & USA & 4 & 4 & 4 & 4 & 4 & 3 & 3 & 4 & 3 & $92 \%$ \\
\hline Tan, Sahin, and Ozdemir (2012) & Turkey & 4 & 4 & 4 & 3 & 4 & 4 & 4 & 4 & 4 & $97 \%$ \\
\hline Uysal, Temel, Ardahan, and Ozkahraman (2010) & Turkey & 4 & 4 & 4 & 4 & 3 & 4 & 4 & 4 & 4 & $97 \%$ \\
\hline Wang, Jiang, Wang, Wang, and Bai (2013) & China & 4 & 4 & 4 & 4 & 4 & 3 & 4 & 4 & 4 & $97 \%$ \\
\hline Yadav and Fealy (2012) & Ireland & 4 & 4 & 4 & 4 & 3 & 2 & 4 & 4 & 4 & $92 \%$ \\
\hline Yava et al. (2009) & Turkey & 4 & 4 & 4 & 4 & 4 & 4 & 4 & 4 & 3 & $97 \%$ \\
\hline Zhou et al. (2015) & China & 4 & 4 & 4 & 4 & 4 & 4 & 3 & 4 & 4 & $97 \%$ \\
\hline
\end{tabular}

Note: ${ }^{1}$ Abstract \& Title, ${ }^{2}$ Introduction and aims, ${ }^{3}$ Method and data, ${ }^{4}$ Sampling, ${ }^{5}$ Data analysis, ${ }^{6}$ Ethics and bias, ${ }^{7}$ Findings/results, ${ }^{8}$ Transferability/generalizability, ${ }^{9}$ Implications, and usefulness $(4=$ good, $3=$ fair, $2=$ poor, and $1=$ very poor) 
Table 2. Topmost barriers to and facilitators for research utilization

\begin{tabular}{|c|c|c|c|}
\hline \multicolumn{2}{|c|}{ Barriers to Research Utilization } & \multicolumn{2}{|c|}{ Facilitators of Research Utilization } \\
\hline Domain & Authors & Domain & Authors \\
\hline $\begin{array}{l}\text { Adopter/Nurse Characteristics: } \\
\text { Lack of awareness about } \\
\text { research }\end{array}$ & $\begin{array}{l}\text { Athanasakis (2013), Breimaier et al. (2011), } \\
\text { Kang (2015), Kocaman et al. (2010), } \\
\text { Morenso-Casbas et al. (2011), Sari et al. } \\
\text { (2012), Schoonover (2009) }\end{array}$ & $\begin{array}{l}\text { Colleague Support for the } \\
\text { interdisciplinary team and } \\
\text { mentored participation } \\
\text { Continuing education as a } \\
\text { personal and professional } \\
\text { commitment }\end{array}$ & $\begin{array}{l}\text { Chau et al. (2008), Cline et al. (2017), Heydari and } \\
\text { Emami Zeydi (2014), Mehrdad et al. (2008), Yadav } \\
\text { and Fealy (2012) } \\
\text { Buhaid et al. (2014), Chang et al. (2010), Chau et } \\
\text { al. (2008), Cline et al. (2017), Heydari and Emami } \\
\text { Zeydi (2014), Mehrdad et al. (2008), Srijana et al. } \\
\text { (2016), Yadav and Fealy (2012) }\end{array}$ \\
\hline $\begin{array}{l}\text { Organization/Setting } \\
\text { Characteristics: Lack of } \\
\text { authority to change practice }\end{array}$ & $\begin{array}{l}\text { Omer (2012), Yava et al. (2009), Schoonover } \\
\text { (2009), Strickland and O'Leary-Kelley (2009), } \\
\text { Buhaid et al. (2014), Wang et al. (2013), } \\
\text { Chang et al. (2010), Atkinson et al. (2008), } \\
\text { Chau et al. (2008), Tan et al. (2012), O'Nan } \\
\text { (2011), Al Khalaileh et al. (2016), Brown et } \\
\text { al. (2010), Cline et al. (2017), Mehrdad et al. } \\
\text { (2008), Morenso-Casbas et al. (2011), } \\
\text { Aboshaiqah et al. (2014), Solomons and } \\
\text { Spross (2011), Heydari and Emami Zeydi } \\
\text { (2014), Sanjari et al. (2015), Oh (2008) }\end{array}$ & $\begin{array}{l}\text { Organizational Support } \\
\text { (funding, infrastructures, } \\
\text { and research facilities) }\end{array}$ & $\begin{array}{l}\text { Chang et al. (2010), Chau et al. (2008), Kang } \\
\text { (2015), Mehrdad et al. (2008), Omer (2012), } \\
\text { Sanjari et al. (2015), Srijana et al. (2016), Tan et al. } \\
\text { (2012), Yava et al. (2009) }\end{array}$ \\
\hline $\begin{array}{l}\text { Innovation/Research } \\
\text { Characteristics: Overwhelming } \\
\text { publication }\end{array}$ & $\begin{array}{l}\text { Zhou et al. (2015), Srijana et al. (2016), Al } \\
\text { Khalaileh et al. (2016) }\end{array}$ & & \\
\hline $\begin{array}{l}\text { Presentation/Communication } \\
\text { Characteristics: Lack of } \\
\text { avilable literature compilation }\end{array}$ & $\begin{array}{l}\text { Sari et al. (2012), Uysal et al. (2010), Yadav } \\
\text { and Fealy (2012), Boström et al. (2008) }\end{array}$ & & \\
\hline
\end{tabular}

